\title{
REFERENCES.
}

Chartres.-Contribution à l'étude de l'ophtalmie purulente des nouveau-nés. Thèse de Doctorat, Bordeaux, 1897.

Coppez.-Des Conjonctivites pseudomembraneuses. Brussels, 1897.

Etude sur la diphtérie oculaire. Arch.d'Ophtal., T. XIX, 1899.

Feer.-Echte Diphterie ohne Membranbildung unter dem Bilde der einfachen katarrhalischen Angina. Correspondenzblatt für Schweizer Aerzte, T. XXIII, 1893

Ginestous.-Ophtalmologie Infantile. Ed. Doin, Paris, 1922.

Goldscheider.-Bakterioskopische Untersuchungen bei Angina tonsillaris und Diphterie. Zeitsch. f. Klin. Med., T. XXII, 1893.

Guilbert.-Arch. d'Ophtal., T. XIII, 1893.

von Herrenschwand. - Die pathogenen Mikroorganismen des Auges. Ed. Urban and Schwarzenberg. Berlin and Vienna, 1927.

Koplich.-Forms of true diphtheria, which simulate simple catarrhal angina. The so-called diphtheritic angina sine membrana. New York Med. Jl., Vol. II, 189 !.

Martin.-Examens cliniques et bactériologiques de deux cents enfants entrés au pavillon de la diphtérie. Ann. de l'Institut Pasteur, 1893.

Morax.-Maladies de la Conjonctive. Encyclop. Franc. d'Ophtal., T. V.

Morax et Elmassian.-Action de la toxine diphtérique sur les muqueuses. Ann. de l'Institut Pasteur, mars, 1898.

Pes.-Giornale Acc Med., Turin, 1897.

Pichler,-Deutschmann's Beit. z. Prakt. Augenheilk., T. XXIV, 1896.

Roger et Bayeux.-Comp. rend. de la Soc. de Biol., mars, 1897.

Sourdille.-Etude clinique, bactériologique et thérapeutique sur la diphtérie oculaire. Arch. d'Ophtal., T. XIII, 1893, et T. XIV, 1894.

Trapezontzewa.-Westnik Ophthai., 1915, and Klin. Monatsbl. f. Augenheilk., T. LX.

Uhthoff.-Ein weiterer Beitrag zur Conjunctivitis diphterica. Berl. klin. Wochenschr., Bd. XXXV, 1894.

\section{DISTURBANCES OF THE VISUAL APPARATUS IN THE TOXAEMIAS OF PREGNANCY ASSOCIATED WITH ECLAMPSIA OR THE PRE- ECLAMPTIC STATE}

B Y

\author{
Lieut-Col. R. E. Wright, I.M.S., DR. K. Koman Nayar \\ and DR. T. Vencatarangum Nayudu \\ GOVERNMENT OPHTHALMIC HOSPITAL, MADRAS
}

IN November, 1933, the first-named writer saw in consultation with Dr. Narayanaswami Pillai of the above hospital a case of "blindness following eclampsia." "A" was a Hindu, aged 18 years ; 18 months before she was nearing full term as a primipara. She had been a big strong healthy girl and never suspected anything wrong till she got fits near the time of her delivery. They were not bad and she consulted Colonel Hingston, at that time Superintendent, Madras Government Hospital for Women and Children. He 
treated her by the veratrone method, then in routine use in his hospital. She was delivered, and after delivery she had very severe fits. She rapidly became blind and a condition of general muscular paresis, loss of sphincteric control, and mental apathy set in. Her child died in three months, but she did not realise what had happened. Gradually her muscle power came back. She began to speak to her relatives and take an interest in things. To all intents and purposes she regained her previous mental and physical vigour, but she remained blind. On examination, vision = H.M. both eyes, pupils round, about $4 \mathrm{~mm}$., reacting sluggishly to light and accommodation. The fundi on either side were absolutely normal in every respect. The urine and blood pressure were reported normal. The diagnosis seemed to be between psychic blindness, this type is not very uncommon here, and a lesion above the third neurone resulting from pregnancy toxaemia. After a careful examination a psycho-neurotic amblyopia seemed improbable and a lesion of the upper neurone attributable to eclampsia was diagnosed. She was three months' pregnant, and, disappointed with western medicine she employed practitioners of indigenous medicine for her second pregnancy. They appeared to stake all on a psychic lesion and assured her that she would recover her sight on being delivered of her second child. With the help of Dr. Narayanaswami Pillai, who has kept in touch with the case, we now know that she was delivered of a child at full term in July this year. There were no fits, nor was there any change in the vision. No record is available of blood pressure or urine examination at this time.

The case was very interesting and we do not remember having seen one exactly like it previously, that is to say, a case in which the vision had been serious!y interfered with in an eclamptic without any evidence whatever of an injury at the retinal level. Colonel Hingston and Dr. A. Lakshmanaswami Mudaliar have permitted us to say that they do not remember having seen a similar case in the last decade. Their experience of eclampsia at the Government Hospital for Women and Children is extensive as may be seen from the reports of this institution. In the last 10 years there were 31,520 pregnancies and 1,199 eclamptics or pre-eclamptics. It is possible, of course, that they may have missed cases of this type in hospital practice, as patients with serious defects of vision associated with pregnancy not uncommonly take their discharge from hospital very soon after delivery, and systematic ophthalmoscopic examination of such women has not been a routine in that hospital. Some post-eclamptics come our way on account of the proximity of the two institutions. Heretofore in the serious defects of vision following toxaemias of pregnancy we have always observed some fundus change, but it does not follow that patients 
affected like "A" have not escaped our observation. In one other case at least, referred to us by Dr. P. Jeffery of the Vellore Medical School for Women, there appeared to be an injury at this level from which the patient gradually recovered without residual changes in the eye grounds, but we will not quote it in detail as malaria and quinine were also possible toxic factors.

Some years ago the late Dr. V. G. Muthayya, at that time in charge of the refraction room of this hospital, undertook at my request to examine the fundi of such cases of eclampsia as were reported to us from the neighbouring Government Hospital for Women and Children. How many cases were observed by Dr. Muthayya is not known-he became ill and died, and his records were lost. He probably did not see more than 20 cases, and our general impression, from verbal communication, is that the bulk of them presented fundi within normal limits. In view of the above, we decided to undertake a fresh series of observations. By the kindness of Colonel C. M. Plumptre, Dr. A. Lakshmanaswami Mudaliar and Dr. Achutha Menon of the Government Hospital for Women and Children, we were given telephonic advice of the admission of patients to the eclampsia wards. We shared the labour of making ophthalmoscopic observations, and long experience of working together has enabled us to attain a practical degree of uniformity in interpreting fundus appearances. It was not possible to see these patients beforehand nor to follow them up after discharge except in a few instances. We saw a series of 27 cases, 28 including case "A," the details of which are conveniently shown in the attached table. It will be noted that there is no record of the state of the urine or blood pressure before admission; this is regrettable, but unavoidable in hospital patients here. A clinical observation of this sort would be more valuable if it were known in how many instances the kidney function was normal before the pregnancy, or, at what stage, if at all, it became impaired, also at what period the blood pressure showed evidences of variation. It was not our intention, however, to make an exhaustive enquiry, but to make a clinical record of the more obvious eye lesions. The first thing that strikes one in the series is the absence of any case of detachment of the retina. In ophthalmic literature the occurrence of detachment in eclampsia has received considerable attention, although it is relatively infrequent. Clapp (in the Amer. Jl. of Ophthal., July, 1919) gives his experiences in Baltimore where he observed six cases of detachment in less than two years, but in the previous 14 years had not seen a case. The number of cases of eclampsia observed is not given. Schiötz found seven instances in 158 eclampsia and threatened eclampsia cases (Klin. Monatsbl. f. Augenheilk., 1921). If we assume that Dr. Muthayya saw 10 cases without an instance of detachment (and we 


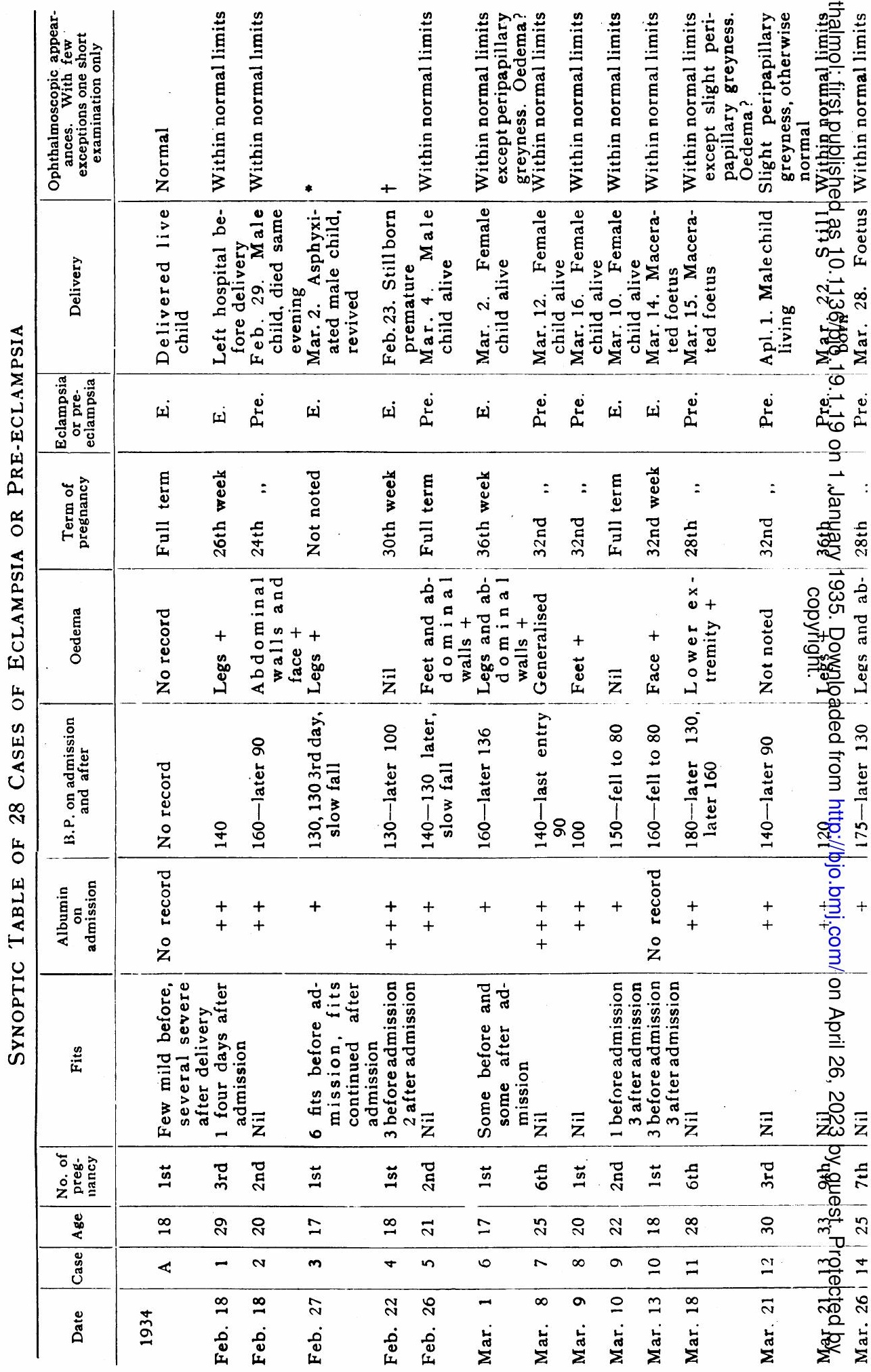


know that this is an underestimate from our conversations with him), we may say that in 37 cases of eclampsia and pre-eclampsia in Madras this complication did not arise. We do not propose to discuss the point, but would remark on the fact that the observation is in keeping with the relative infrequency of retinal detachment in all classes of Indian patients here.

In two instances (Nos. 19 and 23), there was obvious vascular damage as evidenced by recent retinal haemorrhage. In one of these, a young primipara (No. 23), it may reasonably be assumed that the disturbance was dependent on the recent pregnant state, and that she was unlikely to have had a residual lesion of the kidney or earlier retinal lesion. In the other case (No. 19), there had been previous pregnancies and the possibility of a residual kidney lesion, although there were no evidences of old retinal damage. We were particularly interested in looking for evidences of spasm of the retinal vessels in view of the modern conception of the rôle of spasm in the march of events resulting from these toxaemias which may ultimately involve the whole systemic arterioles in permanent damage. Only in one case were we able to see anything of this nature (if we except some appearances of oedema as indicative of temporary spasm), but this was the one case which we $\vec{\bullet}$ were able to observe in a seizure (No. 3). It is highly probable c్ that we missed localized spasm of the arteries such as was describes by Mylius and studied by Wagener (e.g., Jl. of Amer. Med Assoc., October, 1933) and others; time did not permit of prolonged and frequent observations. We might have been more fortunate in so far as the localized spasm is concerned had we been able to pursue prolonged and quiet observation rather than record the result of a hurried visit. We expected, but did not find, instances of obvious local or generalized spasm and oedema such as might account for the temporary depression in vision reported by obstetricians, and the permanent interferences with vision which we have sometimes observed as a sequel to eclampsia associated with late vascular fundus changes. The observations made during the seizure in one case (No. 3) are noted. It will be seen that they did not correspond with a severe generalized spasm such as occurs, for example, in a quinine idiosyncrasy, nor with the localized but definite contractions of the arterioles described in the recent literature. There was only one case (No. 4) of gross and prolonged interference with vision. When seen in the eclamptic ward at the time of admission this case showed a normal fundus picture. Seventeen days afterwards (March 9, 1934) she complained of complete loss of sight. On March 11, 1934 we got intimation of this event and on that day the fundi were normal, but there was no P. L. On the 12th the fundi were greyish, disc margins blurred, with marked temporal pallor and 
peripapillary oedema. On March 22, 1934, she was admitted into the Government Ophthalmic Hospital. Right eye vision = fingers at 2 metres; left eye vision $=$ fingers at 1.5 metres. Fundi showed left disc paler than right, arteries on both sides narrowed, but left narrower than right. She was discharged on April 3, 1934. Right eye vision $=$ fingers at 2.5 metres, with $-3 \mathrm{D} .=5 / 60$; left eye vision $=5 / 60$.

Fundi : Right eye. Disc pinkish within normal limits, arteries narrowed, no other change except that the foveal region showed a dull smoky appearance with loss of reflex. Left eye. Disc definitely pale, otherwise appearances same as right.

On July 18,1934 , the right eye vision $=6 / 60$; left eye vision $=$ fingers at 3.5 metres. The arteries were distinctly narrowed in both eyes, the left disc paler than the right, both showed a waxy yellowish pallor. The foveae showed some slight change on either side, loss of reflex, increased smokiness and fine mottling. The blood pressure was $110 / 70 \mathrm{~mm}$. $\mathrm{Hg}$, the urine free from albumin. The fields were markedly and concentrically contracted; no scotoma for white or colours. Whatever happened during the sudden loss of vision in this case, whether the retinal neurones were damaged by ischaemia secondary to the action of the toxin on the arterioles or by a direct poisoning of the ganglion cells, the late result resembles, in certain respects, the effects of a quinine amblyopia. The vision at first lost as a result of immediate injury was slowly regained in part, but not to the extent one sees in a quinine amblyopia. There was no central scotoma, but the fields were markedly contracted. The retinal vessels were narrowed and the disc showed a definite pallor. The immediate damage to the vessels was followed by permanent arteriolar sclerosis. Such late vascular changes presumably occur in greater or lesser extent when the action of the toxin on the arterioles is sufficient, apart from sudden losses of vision or obvious fundus changes during the toxic state. The less obvious degrees of spasm described in recent literature as of frequent occurrence in the toxaemias of pregnancy may ordinarily precede such permanent arteriolar contractions, but are not necessarily followed by them. The defect in the above case is obviously quite different in its location from that in case "A" described at the beginning of this article. The mode of production may have been the same, the damage to vision gross, but the level at which the injury took place different.

From this limited clinical record of South Indian eclamptic and pre-eclamptic patients the following inferences may perhaps be drawn :-

1. That practical blindness associated with normal eye grounds may follow the eclamptic state, the presumption being that the injury has acted at a higher level than the third neurone. This is 
exceedingly rare here, only one other possible case having been observed in the last 15 years.

2. That loss of vision may also result from an injury actingo at the retinal level either suddenly (usually recovered in whole or in part), or gradually and permanent (due to late changes in $\frac{\bar{c}}{\bar{\phi}}$ the vessels); this is not very rare.

3. That minor injuries may take place involving the retinalœ vessels as evidenced by haemorrhages, oedema and alteration in $\vec{\circ}$ calibre of arteries and veins without immediate interference with vision; such are relatively common.

4. That the lesser spastic phenomena of the arteriolar tree $\frac{\mathscr{\rho}}{0}$ described of recent years were probably missed, owing to the? hurried nature of the ophthalmoscopic observation, rather than $\overrightarrow{0}$ absent, on account of any peculiarity in the local conditions.

5 . That detachment of the retina is probably very rare here $\overrightarrow{0}$ as a sequel to the toxaemias of pregnancy; it has not been observed 9 by us in this condition either in this series or on any previous $\vec{c}$ occasion in the past 10 years.

\section{ON THE STRUCTURE OF HERBERT'S PITS \\ BY \\ ARChIMEde Busacca, M.D. \\ OCULIST IN THE CITY OF SÃo PAULO, BRAZIL}

RePorting to the last Ophthalmological Congress in April, 1933, at Madrid, on a series of observations concerning the trachomatous lesions of the cornea, I maintained that the formations known as Herbert's pits consisted histologically in thickenings of the corneal epithelium which proliferated on those points where the nodules of trachoma had previously appeared.

During a subsequent communication, Pascheff expressed his sur- $\delta$ prise at such an interpretation being maintained. Owing to lack of time then, I was unable to discuss the matter further. Had I을 had time to discuss the subject on that occasion, I should have $\rightarrow$ limited myself to stating that my views were based upon histological 을 researches carried out on a number of pieces of cornea which I N had removed from patients and had studied by means of serial $N$ sections. At the time it was impossible for me to furnish more convincing evidences to support the view that the thickenings $I_{\sigma}^{\omega}$ had taken as corresponding to the pits did really correspond to them. One of the photomicrographs which I had the opportunity of presenting to the Congress, is the one that is seen in Fig.1. It was 